\title{
Michel Brix, L'Éros romantique et le libertinage: à propos d"'Adolphe" de Benjamin Constant
}

\section{Annalisa Bottacin}

\section{(2) OpenEdition}

1 Journals

\section{Edizione digitale}

URL: http://journals.openedition.org/studifrancesi/5996

DOI: 10.4000/studifrancesi.5996

ISSN: 2421-5856

\section{Editore}

Rosenberg \& Sellier

\section{Edizione cartacea}

Data di pubblicazione: 1 mai 2011

Paginazione: 182-183

ISSN: 0039-2944

\section{Notizia bibliografica digitale}

Annalisa Bottacin, "Michel Brix, L'Éros romantique et le libertinage: à propos d"'Adolphe" de Benjamin Constant», Studi Francesi [Online], 163 (LV | I) | 2011, online dal 30 novembre 2015, consultato il 13 janvier 2021. URL: http://journals.openedition.org/studifrancesi/5996 ; DOI: https://doi.org/10.4000/ studifrancesi.5996

Questo documento è stato generato automaticamente il 13 janvier 2021.

\section{(c)}

Studi Francesi è distribuita con Licenza Creative Commons Attribuzione - Non commerciale - Non opere derivate 4.0 Internazionale. 


\title{
Michel Brix, L'Éros romantique et le libertinage: à propos d'"Adolphe" de Benjamin Constant
}

\author{
Annalisa Bottacin
}

\section{NOTIZIA}

MICHEL BRIX, L'Éros romantique et le libertinage: à propos d'“Adolphe" de Benjamin Constant, in «H. B.», n 13-14, 2009-2010, pp. 167-175.

1 Questo interessante studio esordisce con un'analisi centrata su due riflessioni inerenti l'eros romantico, firmate da Stendhal e da Sainte-Beuve. In effetti nel settembre del 1824 , tra le collaborazioni dell'autore grenoblese alla rivista britannica, «New Monthly Review», vi sono due recensioni a opere di Benjamin Constant, la prima dedicata a De La Religion e la seconda a Adolphe, giunto alla $3^{\text {a }}$ edizione, opera di un autore definito da Stendhal «l'un des hommes les plus intellectuels de France» (sTENDHAL, Chroniques pour L'Angleterre, II, 1823, Grenoble, ELLUG, 1982, pp. 237). L'autore del Rouge ben comprese le peculiarità di Adolphe da trarne la seguente conclusione; lo trova in effetti «un roman plus singulier qu'excellent». È anche un altro, comunque, il giudizio di Stendhal evidenziato da Michel Brix e precisamente la definizione di Adolphe quale «marivaudage tragique où la difficulté n'est point, comme dans les romans de Marivaux, de faire une déclaration d'amour, mais une déclaration de haine. Cela fait - continua Stendhal l'histoire est terminée» (ivi, p. 281). Il critico, che condivide il senso di quest'ultima citazione, la accosta al giudizio espresso da Sainte-Beuve che, al pari di Stendhal, evidenzia come nello spazio narrativo del suo secolo, l'alcova sia «la dernière clef» per qualsiasi situazione amorosa. Accostando le citazioni, con indubbia acuità, Michel Brix organizza un approfondimento assai rilevante, partendo dal presupposto se nel Romanticismo si possa parlare solo di amore «spirituel»o se il libertinaggio non sia più un tema ricorrente, come nel Settecento; in effetti, la critica ha tracciato «une ligne de 
démarcation très nette entre l'Éros des Lumières [...], et les conceptions romantiques en matière amoureuse» (p. 167).

2 Ma come non evidenziare che tra gli scrittori romantici circolava l'Érotique comparée di Charles de Villiers, opera edita nel 1806, che sosteneva, come riporta Brix, che «les Allemands sont par nature mystiques et idéalistes, [...] tandis que chez les Français, à l'inverse, dominent les aspirations sensuelles, sans autre perspective»? (pp. 167-68). È comunque noto che l'amore fisico nel primo Ottocento era visto con sospetto, al punto che Lamartine in Raphaël, riscrittura della Nouvelle Héloïse, evita di riportare l'episodio delle notti d'amore vissute da Julie e da Saint-Preux. Adolphe, che raccoglie le esperienze sentimentali del suo autore mostra come le voci della passione siano sempre molto forti. Come ignorare che Benjamin Constant ha ancora una formazione illuministica, essendo egli nato nel 1767, legata alla lettura di opere di autori quali, ad esempio, La Mettrie e Crébillon fils? Per altro «la composition et la publication d'Adolphe interviennent à l'extrême fin de la période qu'on appelle précisément le "crépuscule du libertinage"» (p. 169), allorché furono pubblicate le avventure del chevalier de Faublas, Pauliska di Saint-Cyr e le Liaisons dangereuses. Sade era morto nel 1814. "Ce faisceau d'indice - prosegue Brix - atteste qu'il existe une véritable pertinence à analyser Adolphe comme un roman du XVIII et à voir dans le personnage principal un libertin plutôt qu'un héros romantique» (ivi.). La questione viene dislocata dallo studioso in una serie di esemplificazioni che ridiscutono il problema, evidenziando quanto sia valida l'affermazione precedente nel romanzo di Constant, un récit che certo non deve essere solo considerato, come afferma il suo stesso creatore, «une histoire assez vraie de la misère du cœur humain». 